\title{
Generation Trouble: Reflections on Gay Male Identity, Generational Consciousness, and Social Belonging
}

\author{
RicK H. LEE
}

Rick H. Lee is a doctoral candidate in the Department of English at Rutgers University. His dissertation, Generation Trouble in Gay Male Literature and Culture, analyzes the generation concept as an ideological problem that shapes gay men's relationship to familial succession, social belonging, and historical memory. Part of that dissertation, this article examines the implications of generational thinking in contemporary gay male discourse and social life. He welcomes responses via email at rick_h_lee@hotmail.com.

[Generation's] important development has been towards social and historical uses, beyond the specific biological reference.

- Raymond Williams (140)

The phenomenon of generations is one of the basic factors contributing to the genesis of the dynamic of historical development.

- Karl Mannheim (395)

... to ask ourselves to which generation we belong is, in large measure, to ask who we are.

— Julián Marías (106)

\section{I}

66 T $\mathrm{s}$ There a Gay Generation Gap?" muses Out magazine in a headline on the cover of its October 2001 issue. What at first 1 appears as a genuine question, however, turns out to be merely rhetorical. For the headline leads to two articles that differ not only in focus, but, more revealingly, in their uses of the generation 
concept. In "Youthquake," Mike Glatze and Benjie Nycum approach the concept as a demographic term to consider the emotional and physical isolation of gay youths in rural areas in the U.S. and Canada. In "The Gay Generation Gap," Steve Weinstein draws upon the concept's genealogical dimension to consider the absence of historical memory in urban gay male culture. The difference between the authors' perspectives is more than a matter of geography; by their own admissions, it is also a matter of age: "we're in our 20 s ourselves," admit Glatze and Nycum (54); "I just turned 49," confesses Weinstein (91). Juxtaposing two articles that differ both in their object of study and in their method of inquiry, Out magazine succeeds in showing that there is indeed a "gay generation gap." By the same token, however, the magazine fails to engage in a more meaningful fashion with the debate it aims to set up.

These two Out articles illustrate a larger phenomenon in gay male culture that I call "generation trouble." By trouble, I mean specifically the ways in which the generation concept has come to dominate and saturate - through often competing and contradictory claims - our vocabularies of self-definition and our taxonomies of public collectivity and social belonging. ${ }^{1}$ Especially in the last fifteen years the concept has appeared with increasing frequency as an analytic and experiential category in discussions of gay male identity across a range of gay publics - in the academy and in cyberspace, ${ }^{2}$ as well as in local weeklies and in national magazines. For example, in "The Problems and Promise of Gay Youth," one of the articles featured in the Advocate's "Young and Gay" issue on 16 September 1986, Mike Hippler announced that "there is a new gay generation

${ }^{1}$ At the risk of "situat[ing] lesbianism as a footnote to gay male history" (Fuss 110 ), I want to make the following admission. Although some of what I have to say relates to lesbian culture as well, I also want to keep in mind that the generation concept functions in markedly different ways for lesbians. The uses of the generation concept in lesbian culture are evident in the ways that lesbians negotiate their relationships to, among other things, histories of feminism, the "sex wars" of the 1980s, butch-femme aesthetics, and reproductive culture. See, for example, Freeman; Hayden; Heller; Martinez; Roof; Stein; and Wiegman.

${ }^{2}$ In August 2001, for example, a lively and heated discussion occurred on the listserv <http://www.circuitpartyinsanity.com> about issues of ageism and generational difference in the circuit party scene; the discussion was resumed, more recently, in late April and early May 2002. I thank Vincent A. Lankewish for drawing my attention to this discussion. 
emerging - whose experiences, priorities, and prospects differ significantly in many respects from those of previous generations. It is a different world they face in 1986. It may be a different future they face as well" (42-43). The future Hippler speaks of has come and passed, and the "new gay generation" he refers to has since acquired the name of Generation Q, a youth cohort that came of age in the late 1980s and early 1990s whose members resist gay male identity in favor of a postgay and post-AIDS identity. ${ }^{3}$ The shift from the "promise of gay youth" in the pages of the Advocate in 1986 to worries about the "gay generation gap" in the pages of Out in 2001 is striking and deserves critical attention. On the one hand, the current debates about the generation gap in contemporary gay male culture articulate a familiar narrative of generational difference that reflects the disparate ideologies of different cohorts. On the other hand, today's version also differs from earlier versions of this narrative for at least two reasons: first, the increased visibility of gay youths and elderly gays as social constituencies - unprecedented in the modern history of homosexuality - has demanded far more expansive visions of the needs of diverse gay male subjects; second, the AIDS epidemic has interrupted vital processes of generational transmission in gay male culture. With some important qualifications, the question of whether there might be a "gay generation gap" is certainly worth asking. But we must do so by posing a different set of questions. What constitutes either a gay male generation or a queer generation? More importantly, are the two different in kind or only by degree?

I raise these questions to make two related arguments in this article. First, gay men of different ages use and, in effect, understand the generation concept in different and sometimes competing ways.

${ }^{3}$ To the best of my knowledge, the term "Generation Q" gained currency in the mid 1990s. See, for example, the four-part documentary The Question of Equality, produced in 1995 by Testing the Limits and Channel 4/U.K. for the Independent Television Service, and, in particular, its last installment entitled Generation $Q$, directed by Byrd. In 1996, Bernstein and Silberman edited the anthology collection Generation $Q$; in the summer of 1997 , the Advocate published a special double issue on Generation Q entitled "Generations of Trailblazers," which featured profiles of younger gay men and lesbians in politics, sports, the arts, society, and science and technology. For a summary of crucial events that have culminated in post-AIDS discourse, see Román; on postgay identity, see Signorile. 


\section{4 / Lee}

Second, and concurrently, the generation concept remains at once problematic and productive for gay male identity formations. That the concept can be used and understood as both stems from the fact that it signifies, on the one hand, a normative principle of familial succession and kinship descent, and, on the other, a viable social practice of affiliation among cohorts belonging to different historical generations. Because we often use the generation concept interchangeably, we need to be attentive both to its biologicalgenealogical dimension and to its sociohistorical dimension. Ultimately, I want to propose a theory of the conditional uses of the generation concept, a theory that would at once critique the normative dimension of the concept without necessarily sacrificing its inherent value as an analytic and experiential category that makes possible gay men's self-definition and sense of social belonging.

I have coined the term "generation trouble" to underscore the generation concept's multiple functions in gay male culture - the ways in which it shapes processes of identity formation; secures or fails to secure social belonging; and measures the shifts in collective consciousness about historical events such as the Stonewall riots and the AIDS epidemic. My term generation trouble evokes and is indebted to Judith Butler's groundbreaking work on gender as a necessary but troubling category of identity. In the preface to Gender Trouble, Butler invites us to consider the ways in which "trouble need not carry ... a negative valence" (vii). She puts the matter even more pointedly in her essay "Imitation and Gender Insubordination," where she states: "I'm permanently troubled by identity categories, consider them to be invariable stumbling-blocks, and understand them, even promote them, as sites of necessary trouble" (14). Following Butler's example, and drawing from the foundational works of generation theorists Karl Mannheim, José Ortega y Gasset, and Julián Marías, I wish to promote the identity category of generation as a site of necessary trouble. In developing the theory of generation trouble, I also take as my models Raymond Williams, David Schneider, Brent Edwards, Nayan Shah, and Michael Warner, whose works have productively interrogated certain keywords and concepts fundamental to our cultural vocabulary. In different ways, these critics and theorists have been acutely attentive to the problems of meaning that accrue historically to terms that are integral to "the vocabulary we share with others ... when we wish to discuss many 
of the central processes of our common life" (Williams 14). The uses of the generation concept in contemporary gay male culture demonstrate both a "politics of nominalization" (Edwards 46) and a "politics of assertion" (Shah 481). That is to say, gay male generation trouble describes a struggle over representation as well as a crisis in epistemology concerning different forms of social relations in gay male culture: it is a phenomenon that at once challenges, modifies, and validates the meanings and values of gay male identity formations and social belonging.

In what follows, I first provide a history of the generation concept, before situating it within the context of contemporary gay male culture. I then rehearse and evaluate two essays that, in addition to the two recent Out articles, illuminate the shift in gay men's uses and understandings of the generation concept in the last fifteen years: Arnie Kantrowitz's "Letter to the Queer Generation" and Justin Chin's "Q-Punk Grammar." Throughout, I also examine a host of other sources, drawn from both academic and popular literature, as evidence of gay male generation trouble. The definitional and usage problems of the generation concept in these texts illustrate not only its ubiquity in the gay cultural imagination; they also reveal its profound yet troubling influence in shaping gay men's negotiations of their identity formations and their perceptions of Stonewall, AIDS, and the coming-out process - all of which, in turn, contribute to their sense of belonging, or not belonging, to gay male culture and history. Because the concept increasingly organizes our ways of thinking and modes of being, we need to think carefully about our uses and understandings of the generation phenomenon in gay male culture. In short, we need to examine the concept's very usefulness as a descriptive and analytical term that registers the range of our experiences. As gay men, we have a stake in recognizing that our uses of the concept will affect its meaning and value for succeeding gay generations in the future.

\section{II}

Before situating the generation concept in relation to gay male culture, I want to sketch out its history and context. In Indo-European languages, the etymology of the term derives from the Greek root of the word genos (gen-), meaning "to come or bring into being" or "to come into existence" (Strauss / Howe 433), and from the Latin 
generare, meaning "to reproduce one's own kind" (Williams 140). The concept is a defining characteristic of Classical literature - in Homer's account of the Trojan War in the Iliad, as well as in Hesiod's explanations of the genealogy of the gods in Theogony and of the five ages of man in Works and Days (see Nash). It is also a defining characteristic of Judeo-Christian traditions and their various genealogical narratives in both Old and New Testaments (Strauss / Howe 433-34). The generation concept began to be developed as a secular idea in the West in the nineteenth century, when the formation of social classes and the rapid industrialization of Europe contributed to the stratification of age groups (Jaeger 275-76) and to the elaboration of an ideology of youth (Kriegel 26-27). Since then, it has come to occupy an increasingly important place in the Western cultural imagination, generating much debate both in popular and in academic discourses about its meanings and coherence. The concept has several distinct but overlapping meanings: a principle of familial succession and kinship structure; a social practice of affiliation among cohorts; a phase or stage of the life course; and an index of historical periods (Kertzer 126). Moreover, with technological advances and increased consumerism, it has frequently come to be used to describe successive types of manufactured products (Williams 141).

Increasingly, the generation concept appears in a range of contexts that reflects this spectrum of meanings. Within the academy, for example, it is used to structure discussions between feminists or between literary critics about shifts in disciplinary methods, objects of study, and political ideologies (see Herman; Looser / Kaplan). It is also used, in more empirical fashion, to structure discussions between social scientists, for whom the term remains a primary analytic category for research in the fields of demography, political science, and social policy. Within popular culture, it is used to market products to consumers, from soft drinks and dolls to denim jeans and luxury cars, in each case suggesting not only new consumer demographics but also new products (e.g., "the Pepsi generation"; "the Generation Girls," Barbie's new friends from Mattel; the retailer GAP markets its clothing "for every generation"; "the new Jag generation"). And most familiar to us, it is used in popular culture to describe the emergence of new social types in an ever-changing and ephemeral youth culture - from "Generation X," the adolescents and young adults of the 1990 s, to their twenty-first-century cohorts, the "Millennials," to 
the "Organization Kid," a new breed that ostensibly belongs to both generations. ${ }^{4}$ Given these rich possibilities, the generation concept deserves its status as one of the keywords that helps to define and make intelligible modern culture and society (Williams 140-42).

The generation concept also functions as a keyword in gay male culture, where it is used to reference just as many of its possible meanings. Consider the two Out articles with which I began my reflections on gay male generation trouble. In "Youthquake," Glatze and Nycum use the generation concept as a strategy to claim solidarity with other gay youths and to discuss issues that confront them as a demographic constituency - such as their sense of isolation within and outside the gay community, the violence they encounter in school, and the high rate of gay teen and youth suicides. In their article, they describe their travels across the United States and to Halifax, Canada, in search of "Young Gay America." "Our goal," they explain, "is not only to prove that gay teens exist and are thriving everywhere but also to give them a better way to express themselves, feel less isolated, learn from each other's experiences, and come to understand their importance in the world" (56). In the process, they address what they see as "the institutionalized gay indifference to youth issues" in gay culture. "It's up to youths themselves and compassionate parents to fight a battle that probably should be on the top of the gay community's list. Is it really more important," they ask provocatively, "to recognize gay spouses than it is to stop violence in schools?" (62). For Glatze and Nycum, the generation concept affords them the opportunity not only to speak on behalf of gay youths in "Young Gay America," a vibrant yet neglected social constituency that in part makes up contemporary gay male culture, but also to call into question what they see as the

${ }^{4}$ See Brooks; Coupland; and Howe / Strauss. Interestingly, what Coupland calls in his novel "mid-twenties breakdown" (27) has since become a distinctly postmodern phenomenon, with the recent publication of Robbins and Wilner's self-help book, Quarterlife Crisis: The Unique Challenges of Life in Your Twenties. The book stands as one of the most striking, if bizarre, confluences of the generation concept being used both as a marketing tool and as a descriptive category - in this case, the introduction of "quarterlife crisis," a new stage of the life course that supposedly precedes "midlife crisis," its later counterpart. On a different note, the tragic events of 11 September 2001 have introduced what B. Kantrowitz and Naughton call "Generation 9-11." 
misdirected energies of activists who support the normative and assimilationist political agenda of gay-marriage.

In "The Gay Generation Gap," the other article featured in the October 2001 issue of Out magazine, Weinstein uses the generation concept to answer the question, posed as the subtitle of his article: "Why can't over-40 and under-35 gay men communicate?" (10). In doing so, he raises important questions about cultural memory and processes of generational transmission in gay culture. According to Weinstein, "Before Stonewall, secret codes - like touching your nose with your index finger, a red tie, or a nosegay in a lapel, even the location of bars - were part of gay lore passed down to newcomers ... With the mainstreaming of gay culture, there's no need for a secret set of shared references. All of which makes it harder for gay men to communicate. If there are fewer and fewer common touchstones," wonders Weinstein only half facetiously, "what is there to talk about over cocktails?" (91). That "gay lore" is prevented from being transmitted across the generations, according to him, contributes to and is a direct consequence of "our [culture's] lack of an institutional memory." "You don't study gay rights in school, and you don't learn to be gay in college," Weinstein concludes. "Such things are passed down, one generation to the next, and if the generations aren't mixing, everything we had will be lost" (109). Although Weinstein's differentiation between "over-40" and "under35 " gay men suggests that he, like his younger counterparts Glatze and Nycum, aims to speak on behalf of a particular constituency, he is more interested in using the generation concept to underscore the difficulties of forging and sustaining forms of generational consciousness in contemporary urban gay male culture. ${ }^{5}$

Reading these two Out articles side by side shows not only that younger and older gay men use the generation concept differently, but that they understand its purpose and value differently as well. While Glatze and Nycum want younger gay men to "learn from each

${ }^{5}$ Weinstein's worry that there is a lack of communication and interaction between older and younger gay men implicitly touches upon the relationship between mentorship, friendship, and inter- or crossgenerational social relations in gay male culture. For various critical approaches to and discussions of this topic, see: Adam; Greenberg (esp. 26-40); Halperin; Herdt / Boxer; Litvak; Nardi; and Weston (esp. 121-22). For fictional and autobiographical treatments, see: Bartlett, Ready; and Quinn. 
other's experiences," Weinstein wants them also to learn from the experiences of older gay men. While Glatze and Nycum stress "the institutionalized gay indifference to youth issues" in gay culture, Weinstein worries about its "lack of an institutional memory." Glatze and Nycum use the generation concept as a strategy to understand the present; Weinstein uses it as a strategy to understand the present's relation to the past. Although both articles' uses of the generation concept are valid - and even predictable given the range of overlapping meanings that the concept encompasses - they also need to be understood as different. Gay men use the generation concept as a register of their age-specific needs and experiences, one that deeply structures not only their negotiations of their personal identity but also their definitions of what it means to belong to a public collectivity. The generation concept remains an effective category because it provides gay men with empowering modes of affiliation and identification with others situated in similar generation locations - and, as the two Out articles also imply, with equally effective modes of disaffiliation and disidentification with others belonging to other generations.

How readers of these articles interpret the generation concept is also worth noting. For example, the December 2001 issue of Out reprints a letter by Mark Morale of Los Angeles in response to Weinstein's "The Gay Generation Gap." "Steve Weinstein," Morale writes, "takes a condition that is prevalent throughout humanity and tries to make it a gay issue. The way I see it, there's no difference between a generation gap among gays and one among MexicanAmericans, Republicans, or people who wear blue jeans ... I don't need Judy Garland lore passed down to me to know how to love another man intimately" (10). Morale astutely challenges Weinstein's proscriptive vision of what should or should not count as cultural references, what should or should not constitute part of "our" institutional memory. But to base such a challenge, as Morale does, on the false assumption that the generation phenomenon is "a condition ... prevalent throughout humanity" and thus not a "gay issue" is to miss the point entirely. The generation concept is not a human universal category, as Morale would lead us to believe; on the contrary, it is definitively a cultural category whose specific functions in gay male culture invite critical and theoretical elaboration. As a result, we need to interrogate the generation concept 
in order to broaden and deepen our understanding of its profound, if problematic, impact in structuring the gay social world.

\section{III}

We need to make generation a gay issue because there are consequences in the choices we make about our generational identifications and affiliations. As generation theorist Julián Marías puts it, "to ask ourselves to which generation we belong is ... to ask who we are" (106). Who we are is up for debate, of course - are gay male and queer generations different in kind or only by degree? Social scientists working in lesbian and gay studies, who focus on the intersection between gender, sexuality, age, and generation, have begun to provide some answers to this question. In their study of the Horizons youth group in Chicago, for example, anthropologist Gilbert Herdt and psychologist Andrew Boxer propose a cohort system of four historical age-groupings that constitute the gay and lesbian generations that came of age in the twentieth century: Cohort One, after World War I; Cohort Two, during or after World War II; Cohort Three, after the Stonewall riots in 1969 and the advent of gay liberation in the 1970s; and Cohort Four, during the age of AIDS (6-13). Situating these different cohort groups within their specific historical contexts, Herdt and Boxer show that gay and lesbian generations, like other types of historical generations, emerge and are made intelligible through the occurrence of particular historical and social events. "The individual does not invent these grand historical events or create the relevant cultural categories," they explain, "but through social development the individual participates in collectively shared experiences, linking himself or herself to other persons of similar status, according to where they were at the time and what they did in relation to the historical events" (8). Herdt and Boxer stress the importance of our approaches to and interpretations of historical events - that is, what we do in relation to them. To anticipate my discussion, I suggest that Generation Q's view, which would most likely claim that gay male and queer generations are different in kind, is misguided and ultimately self-defeating, since it both stems from and is a reflection of a distressing lack of historical knowledge about contemporary gay male culture.

The Stonewall riots and the AIDS epidemic are significant not only as historical markers, but also because they have transformed, 
in different and profound ways, gay men's relation to the generation concept. Stonewall created new scenes of extrafamilial sociability for gay men, and introduced, with those scenes, empowering modes of affiliation and identification by which individuals could locate themselves in relation to the collective within history. In the 1970s and 1980s, many urban gay men in the United States and elsewhere viewed Stonewall as a pivotal frame of reference in the creation of an emergent cultural consciousness, as well as a strategy to distinguish between gay male generations: pre-Stonewall, Stonewall, and post-Stonewall. As a result of Stonewall and the ensuing gay liberation movement, gay men were empowered to "come out of the closet," an experience that was seen not only as a personal choice or an individual rite of passage, but also as part of a larger political project to claim a collective identity based on fighting homophobia and sexual oppression. During the last two decades, the AIDS epidemic completely altered gay men's positioning of themselves in discourses of generation - especially in the context of the concept's definition as a stage or phase in the trajectory of the life course. Witnessing the deaths of lovers, friends, and numerous others as a result of HIV/AIDS, and facing the possible truncation of their own lives, gay men were forced to confront the intimate connections between their desires and mortality.

Stonewall and AIDS figure prominently in Arnie Kantrowitz's "Letter to the Queer Generation" and Justin Chin's "Q-Punk Grammar," two essays that explicitly use the generation concept as a framework for discussing gay male identity formations. Appearing in the New York City weekly $N Y Q$ in 1992, "Letter to the Queer Generation" was written in response to the irreverent views made by the editors of the Toronto-based queer zine Bimbox following the death of film critic and AIDS activist Vito Russo. ${ }^{6}$ To illustrate the multiple shifts in Kantrowitz's uses of the generation concept, I quote

${ }^{6}$ The Bimbox editors, "Johnny Noxema" and "Rex Boy," had launched an "inning" campaign of prominent gays and lesbians that, in their view, "defile[d] the good name of our people." When a reader wrote back to protest the inclusion of Vito Russo on the "inning" list, the Bimbox editors responded with: "Just "cause someone has AIDS doesn't mean they're exempt from being labeled an asshole. Russo is/was/ and will remain one of the most miserable disgusting insufferable clones ever to enter the public eye. Honey, rest assured that we were well aware of his medical condition 
at length his explanation to the Bimbox editors and, more generally, the readers of their zine who belong to the queer generation:

We don't come from nowhere. When Larry Kramer and Vito Russo watched Vito's last Gay Pride March in 1990, thousands of ACT UP activists shouted up the balcony, "We love you, Vito!" (Take that, Bimbox! You'll never hear the like.) My lover, Larry Mass, heard Larry Kramer say to Vito, "These are our children." Queer Nation is the child of ACT UP, which is the stepchild of GMHC [Gay Men's Health Crisis]. GAA [Gay Activists Alliance] gave birth to the Gay Teachers Association, Lambda Legal Defense and Education Fund and a host of other groups. GAA in its turn was the child of its forebears, the Gay Liberation Front, the Mattachine Society, the Daughters of Bilitis, the Society for Individual Rights, even Magnus Hirschfeld's Institute for Sexual Science in pre-Nazi Germany. Queer people are not newly born, only newly named. You have a history, and you should not only be proud of it, you should learn from it.

I know that oedipal rebellion against our predecessors is an important step, as is reinventing ourselves in each generation, but reinventing the wheel as well is a waste of valuable energy and time. My gay generation rebelled against the Mattachine Society because we considered it too obsequious and against the Gay Liberation Front because we found it too doctrinaire, but we learned things from their experience, as you should learn from ours ...

The "gay" generation is in the process of its mid-life crisis. After fomenting amazing changes in our culture, we suddenly find ourselves uncomfortable with more change - a sign that our day is drawing to a close. It is a reminder that we are all one step closer to death (as if a generation traumatized by the grim spectacle of AIDS needed any reminders).

at the time our inning list was [put] together, and to be honest, we're elated he's off the planet ... Oh sure, Vito's finally dead and we got our wish and we should just drop the whole thing, but we won't be satisfied until we dig him up and drive a stake through his filthy film queen heart" (qtd. in Blasius / Phelan 812). 
I thought I had come from the best era of all. I had survived the oppression of the ' $50 \mathrm{~s}$, participated in the social experiments of the ' $60 \mathrm{~s}$, and emerged from the closet into the sunlight of the '70s, managing to have a great deal of fun and fulfillment before the plague years of the ' $80 \mathrm{~s} . .$.

Good luck being queer. I hope you really have fun, and I hope you make us proud of you. (816-17)

Kantrowitz's "Letter to the Queer Generation" can be read in at least two ways. The author displays a remarkable ability in manipulating the generation concept, maneuvering, as he does, through each of the concept's common definitions: as biologicalgenealogical phenomenon ("Queer Nation is the child of ACT UP"); as sociohistorical phenomenon ("Queer people are not newly born, only newly named"); as a description of a phase or stage of the life course ("The 'gay' generation is in the process of its mid-life crisis"); and, finally, as an index of historical periods ("I thought I had come from the best era of all"). At the same time and despite such maneuverings, Kantrowitz fails to disguise his genuine struggle to make sense of the normative dimensions inherent in the generation concept. His chronological account of postwar gay history articulates a familiar narrative of generational difference between cohorts during various historical moments. Yet for Kantrowitz to claim successfully that same-sex social identities are variable and historically contingent, he must also rely on the language of reproduction and procreation (e.g., "stepchild," "gave birth to," "child of its forebears," etc.). For him to contextualize the existence of homosexual/homophilic, gay, and queer generations within the framework of the social and the historical - that they constitute different cohort groups and, thus, distinct collective entities - he must also position them within the framework of the biological and the familial. In short, for him to argue for these various same-sex generations as sociohistorical phenomena, he must simultaneously argue for their existence as biological-genealogical phenomena. Even his important qualification that "Queer people are not newly born, only newly named" gets deflated when he once again situates his critique within the genre of the family romance and "oedipal rebellion." That Kantrowitz is unable to make his claim without recourse to the language of procreation foregrounds the extent to which reproductive sex, as Michael Warner shows in a different context, "has become an even 
more pervasive measure of value in modernity ... Whether we bear children or not, our lives converge on a future that continues to be imagined not as the activity of other adults like ourselves, but as the inheritance of children - our donatees, our surrogates, our redeemers, our alibi" ("Irving's" 776). The projected future proposed by Kantrowitz is teleological, one inhabited by imaginary children who will correct, or even redeem, the mistakes of the past: "we learned things from their experience," he writes of the pre-Stonewall generation in his admonishment to Generation Q, "as you should learn from ours."

Kantrowitz is not alone in confusing, whether strategically or not, generation as a biological-genealogical phenomenon and generation as a sociohistorical phenomenon. Performance artist Justin Chin also uses the generation concept to frame his discussion of gay male identity in "Q-Punk Grammar," an essay that first appeared in the anthology Generation $Q$ (1996), and was later included in Chin's own collection Mongrel (1999). "Q-Punk Grammar" presents further evidence of the ways in which the language of reproduction and procreation shapes, both implicitly and explicitly, gay men's relation to and understanding of the generation concept. "The gay community is experiencing a great generational gap," Chin notes:

It's a vicious cycle; each generation feels it has cornered the market on what it's like to be gay. The older generation tells us what it was like to be really gay back then, when they had: Donna Summer, when she meant something; ... sex without condoms; venereal diseases that didn't outright kill you; and those insidious little homosexual mustaches. My generation tells the younger queer brats what it was like to be queer back then, and how they will never know what it was like: to sit in a room of sixty people on a Wednesday night and try to reach consensus on something; ... to be at a kiss-in when a kiss-in meant something; to be so filled with anger and a strange hope at an AIDS demonstration; [and] having to defend using the word queer ...

I look in my closet and I see that I have inherited a gaggle of colored drag queens tossing bricks at cops who look suspiciously like uniformed queens in a leather bar ten or twenty years later ... I have inherited a virus, a wrecked community, memorials and Names Quilts, clinical trials and 
the AIDS industry as a viable and "noble" career choice. (32-34)

Like Kantrowitz, Chin must resort to the language of life course that is, the structuring of life as a narrative, whose intelligibility must adhere to categories such as age, career, maturity, inheritance - to make his claim that the "gay community is experiencing a great generational gap." In the end, Chin, while aiming to dislodge the normative structures that, in his view, contribute to the cyclical nature of generations, nevertheless recycles and recirculates the logic of reproduction and inheritance. Although this maneuver dulls Chin's otherwise sharp critique, it does underscore the inherent difficulties of using the generation concept without succumbing to vocabularies of life course and reproduction. No doubt Chin himself recognizes these seemingly insurmountable challenges; perhaps they are the reasons that lead him to declare, in the conclusion of "Q-Punk Grammar," his disenchantment with identity politics: "Let the young ones be queer the way they want to be queer, as long as they are queer, as long as they find among themselves each other to love." Chin ends with the remark: "I've given up the dream of the Queer Nation. Race, class, gender, ideologies, and values will always divide us ... I have no idea what it is to be gay or queer anymore; nor do I care. I am so over being queer, and I don't care what I call myself or what anyone else calls me; it's all a matter of convenience these days" (32-34). I suspect that, in large measure, Chin's disenchantment articulates less his refusal of sexual identities and more his attempt to underscore the complex intersection of sexuality with class and, specifically, with race and ethnicity. Gay men of color recognize that their refusal of heterosexuality often puts them at risk of becoming estranged from their own familial and cultural traditions - an issue that deserves more extended treatment than I can provide here (see also Herdt / Boxer 241). In "Q-Punk Grammar," Chin proposes a new lexicon by which to reconceptualize the possibilities, conditions, and limitations of various kinds of identity - not as identities per se, but, rather, where appropriate and necessary, as matters of convenience.

Both Kantrowitz and Chin attempt to illustrate that the generation phenomenon in gay male culture is a product of social and historical events. Both, however, must rely on the language of reproduction and procreation to do so. Their respective reflections articulate not only a struggle over representation concerning kinship 
and other forms of social relations in gay male culture, but also how those collectivities are conceptualized in the first place. Social scientists and queer theorists have shown the ways in which nonheterosexuals have succeeded in expanding traditional and familiar notions of the family. In Families We Choose, anthropologist Kath Weston poses a set of intriguing questions that are relevant to gay male generation trouble. "What is all this talk about gay families?" she wonders. "Where did those families come from, and why should they appear now? ... Are gay families inherently assimilationist, or do they represent a radical departure from more conventional understandings of kinship? Will gay families have any effect on kinship relations and social relations ...?" (2). In a similar manner, Jeffrey Weeks, Brian Heaphy, and Catherine Donovan, in their study Same-Sex Intimacies, observe that "It is surprising ... that the growing recognition of relational rights for non-heterosexuals should be expressed in the language of the family. What significance can we read into this?" (15). According to them, "The appropriation of the language of the family by many non-heterosexuals can ... be seen as a battle over meaning, one important way in which the sexually marginal are struggling to assert the validity of their own way of life" (17). These scholars have contributed much to our understanding of nonheterosexuals' reconfigurations of family and kinship. With these studies in mind, I propose that Kantrowitz and Chin struggle, in their respective essays, to appropriate and denaturalize the generation concept in the context of gay male social and sexual identity formations. Equally importantly, I value their attempts because both men possess a deep understanding of the historical events that have led them to reflect on the generation concept.

\section{IV}

The slippages that characterize Kantrowitz's and Chin's uses of the generation concept are pervasive not only in gay popular culture but also in the academy. For the same kinds of slippages are evident in the work of social scientists, who "also fall into the tendency, characteristic of generational studies, of a slippery, ambiguous usage that blurs distinctions that should be clarified" (Spitzer 1354). An understanding of generations as sociohistorical phenomena depends upon - indeed, remains deeply embedded within — an understand- 
ing of generations as biological-genealogical phenomena. In other words, although the generation concept is still used to measure time and historical progress and to organize the life course into a sequence of life phases, it is more often used interchangeably, to signify, on the one hand, familial succession and kinship descent, and, on the other, extrafamilial affiliations among cohorts or coevals. Even the most careful of theorists struggle to dislodge fully the conflation between generations as biological-genealogical phenomena and generations as sociohistorical phenomena. Hans Jaeger, for example, suggests that the "concept 'generation' is used in different ways":

The naïve and original meaning of generation is without a doubt a biological-genealogical one. It indicates that descendants of a common ancestor take on average about thirty years to marry and have children. This is not only the natural conception today; it is also the conception of the classical tradition, as, for example, of the Old Testament and of Greek poetry and historiography. The historical notion of generation ... originates out of the biological-genealogical concept with an additional assumption, namely that there exists a connection between the continuing process of the succession between fathers and sons and the discontinuous process of social and cultural changes. (274)

Using the language of origins and reproduction - "natural conception," "originates," "succession" - Jaeger assumes that sexuality is always normative and reproductive. Given the term's etymology, it is hardly surprising that the generation concept inheres most insistently in its relation to the ideology of reproduction. I isolate Jaeger's explanation, however, because it is evidence of the difficulties involved in - and of the need for - interrogating and denaturalizing the generation concept within the context of nonnormative and nonreproductive sexualities. Put another way, although generation now more frequently refers to age cohorts rather than to family and kinship, such a discursive and epistemological shift still secures the status of normative heterosexuality; whereas it once implied the reproduction of familial and kinship structures, it continues to guarantee the reproduction of sociocultural relations.

It has been my intention thus far to encourage the denaturalization of the generation concept. But, at the same time, my readings of the two Out articles and of Kantrowitz's and Chin's essays also 
demonstrate that gay men's engagement with cultural generativity cannot be guaranteed in advance. The inextricable connection between the generation concept's two main definitions - as biological-genealogical phenomena and as sociohistorical phenomena - presents the most trouble to gay men and their uses of the idea. Since biological and genealogical reproduction are inseparable (Erikson 266-68; Kotre), gay men struggle in securing cultural generativity - the production, transmission, and reception of values and practices across generations - because they tend not to have recourse to biological generativity. For any historical generation to survive and evolve, it must succeed in transmitting its values and practices to members of the next generation, who in turn participate in the reception of those values and practices - by embracing, modifying, or rejecting them. Unlike heterosexuals and even lesbians, most gay men have had to create and improvise different strategies through which to engage in and secure cultural generativity, mainly because of their nonparticipation in biological reproduction and child-rearing, and, in the last two decades, because of the AIDS epidemic.

That the generation concept remains firmly rooted in the ideology of reproduction should alert us to its normative dimensions. Let me be absolutely clear: I am not suggesting that gay men should refrain from using the generation concept. Rather, I am suggesting that we recognize the ways in which the generation concept remains inextricably connected to "heteronormativity," a term that Michael Warner and Lauren Berlant use to describe the wide and diffuse range of "institutions, structures of understanding, and practical orientations that make heterosexuality seem not only coherent ... but also privileged" (548n2). Heteronormativity prevents gay men from creating and sustaining institutions for common memory and, in the process, interrupts and forecloses the possibility of generational transmission. The slippages in Kantrowitz's and Chin's uses of the generation concept are in many ways problematic because they recirculate and shore up the logic of heterosexuality and the intelligibility of the reproduction narrative. But they also show that the generation concept, despite or, rather, because of its multivalent capaciousness, remains useful as an analytic and experiential category for many gay men. That the concept has appeared with increasing frequency in discussions across a range of reading publics strongly 
emphasizes its importance and relevance to gay men's negotiations of their identities and sense of social belonging (or not belonging) to gay male culture and history. That it has been used, at the same time, in radically different ways just as strongly suggests the generation trouble in gay male culture. Our goal, therefore, is not to refrain ourselves from using the generation concept. On the contrary, we need to continue, as Raymond Williams persuasively suggests, to commit ourselves to the task of "contribut[ing] to certain kinds of awareness and certain more limited kinds of clarification by taking certain words at the level at which they are generally used" in everyday life (24).

V

Given the difficulties of thinking about the generation concept outside the framework of reproductive culture, and given that it can be used as a strategy of simultaneous identification and disidentification, can we then use it effectively to theorize the formation and transformation of gay male social and sexual identities? Yes and no. The work of sociologist Karl Mannheim justifies my reservations concerning the possibilities, conditions, and limitations of gay men's uses of the generation concept. Within the context of what Mannheim calls "the sociology of knowledge," the generation concept represents "one of the indispensable guides to an understanding of the structure of social and intellectual movements" (361-62). In his groundbreaking essay "The Problem of Generations," Mannheim radically reconceptualizes generations as social and historical phenomena rather than as biological and genealogical phenomena. He finds equally inadequate the liberal-positivist tradition and its quantitative approach to generations as an "objective measure of unilinear progress," as well as the romantic-historicist tradition and its qualitative approach to generations as articulating an "interior time that cannot be measured but only experienced" (356). In his view, both schools of thought fall short of fully addressing the problem because each, in its own way, conceives of generations as intelligible only in relation to a biological rhythm that must adhere either to the patterns of the life course or to the process of familial succession. According to Mannheim, "It is a complete misconception to suppose, as do most investigators, that a real problem of generations exists only in so far as a rhythm of generations, recurring at unchanging intervals, can 
be established. Any biological rhythm," he argues, "must work itself out through the medium of social events" (361). Reframing the problem of generations in relation to the social rather than to the biological, Mannheim conceives of generations as consisting of groups of individuals of roughly the same age, whose experiences of events during particular historical moments bind them to their cohorts, coevals, and peers, and, at the same time, differentiate them from their contemporaries in other age groups and from members of previous and later generations. "Were it not for the existence of social interaction between human beings," Mannheim maintains, "the generation would not exist as a social location phenomenon; there would merely be birth, ageing, and death. The sociological problem of generations therefore begins at that point where the sociological relevance of these biological factors is discovered" (366). By underscoring the primacy of social interaction and, in effect, proposing a theory of human relationality, Mannheim illustrates that the generation concept fundamentally shapes processes of identity formation. That is, the concept endows individuals within the same or proximate generation locations with empowering and expressive modes of extrafamilial affiliation and identification with their cohorts, coevals, and peers.

That the generation concept makes available to cohorts a means with which to define their identity in relation to others belonging to similar generation locations vitally suggests its potential applicability to analyses of gay male culture and identity. In many respects, the concept is ideal because it makes possible an understanding of the emergence of gay male culture as a social entity and, in turn, the existence of its constituent members as social actors. Moreover, because gay men share as their common frame of reference their same-sex desires, their daily struggles with homophobia and AIDS, and their exclusion from normative reproductive culture, many find appealing the scene of extrafamilial sociability and the forms of affiliation and identification that the generation concept makes available and sustains. In other words, our generation location secures for many of us forms of solidarity with others similarly embedded in a heteronormative cultural landscape. The sociohistorical dimension of the generation concept provides us, moreover, with a viable alternative that, in many ways, compensates for our exclusion from the biological-genealogical dimension of the concept. 
Notwithstanding its potential applicability to analyses of gay male identity and culture, the generation concept also presents particular challenges and limitations that need addressing. According to Mannheim, there is "a tendency 'inherent' in every social location," whether it be class-based or generation-based, meaning that "the experiential, intellectual, and emotional data which are available to the members of a certain society are not uniformly 'given' to all of them" (366). In his view, "even where the [experiential, emotional, and] intellectual material is more or less uniform or at least uniformly accessible to all, the approach to the material, the way in which it is assimilated and applied, is determined in its direction by social factors" (366-67). Consider, for example, the Stonewall riots and the coming-out process - two important touchstones that are, arguably, part and parcel of the intellectual, experiential, and emotional data or material accessible to most, if not all, gay men. Yet, depending on our generation location, we view and approach that archive differently. "'Stonewall' is the emblematic event in modern lesbian and gay history," writes historian Martin Duberman in his preface to Stonewall, and "has become synonymous over the years with gay resistance to oppression" (xvii). Historian John D'Emilio makes a similar argument by suggesting that gay men and lesbians, in coming out en masse during the early period of the gay rights movement, participated in demonstrating the inextricable connection between the personal and the political (Sexual 235). The coming-out process secures not only an individual's sexual identity but also his social identity. As a ritual that marks an individual's entry into the gay social world, the coming-out experience signifies a defining moment in gay male identity formations (Herdt / Boxer 14).

But our expectations of what fulfills our entry into and sense of belonging to gay male culture have changed significantly, and, in the process, so has our repertoire of shared cultural references. Many now view differently the primacy of Stonewall and the act of coming out, and, consequently, their respective functions as a historical marker and a rite of passage. For example, Robin Bernstein and Seth Clark Silberman propose, in their introduction to the anthology Generation $Q$, that for members of Generation $\mathrm{Q}$, "The closet has become a temporary convenience, a practical safety measure, a tool to use in particular circumstances, a toy to play with, rather than a constant, coercive presence. As the closet becomes less rigid, more 
permeable, and less central, so too does the initial act of coming out"; "coming out," they conclude, "is no longer necessarily the primary rite of passage for queer youth" (xvi). We certainly need to recognize that some if not many gay youths find valuable the performative nature of identities. But we need also to consider that gay people claim their sexual identity not only during their teens and twenties but also later in life. For these countless others, the process of coming out is still a necessary and empowering rite of passage that marks and secures their entry into the gay social world. In short, it is not quite enough for members of Generation $Q$ to note or to perform the changes in the meanings of the closet, without also recognizing that some may find the notion of identity-as-performance anathema.

Ultimately, we need to keep in mind - lest we forget - the pervasiveness of the closet as a deeply entrenched epistemology and way of life in modern Western culture (see Sedgwick). For this reason, we need to struggle to change the culture in which coming out of the closet continues to be perceived as a necessary experience for the constitution of gay male identities. Paradoxically, such a radical transformation of the meanings of the closet can only occur if we take the preliminary step of accepting, rather than dismissing out of hand, the generation concept's intimate connection to the act of coming out. For many of us, our sense of generational belonging is secured in relation not to our age, but, rather, in relation to when we came out of the closet to claim our social and sexual identities (see Escoffier 121). To the extent that generation signifies, among its four common definitions, a stage or phase of the life course, and to the extent that coming out secures our sense of social (read: generational) belonging, we need to recognize their interrelationship as one of the conditional uses of the generation concept. Doing so would allow us to critique the normative dimension of the generation concept, along with mainstream culture's expectation that coming out must remain the sine qua non of our identity constitution, and, at the same time, allow us to retain the concept's inherent value as an analytic and experiential category that makes possible gay men's self-definition and sense of social belonging.

I see the generation concept's connection to, among other things, the process of coming out as an opportunity for exploring the commonalities gay men share with members of Generation $\mathrm{Q}$, and 
vice versa. Bernstein and Silberman, however, use the concept as an occasion to differentiate themselves and their cohorts from previous gay and lesbian generations. They write in their introduction to Generation $Q$ :

As the post-Stonewall generation comes out, we often find a chasm between our experiences and perspectives and those of the lesbians, gay men, bisexuals, and transgendered people who came before us. We are members of the so-called Generation X ...

As young lesbians, gay men, bisexuals, and transgendered people, however, we differ from not only our gay forebears but also our straight peers. We are not just " $\mathrm{X}$ " but "Q"-Queer, a word embraced by our generation. (xv) To my earlier question about whether gay male and queer generations are different in kind or only by degree, Bernstein and Silberman would probably answer in kind. I would not begrudge them this view: $\mathrm{I}$, too, recognize that there are significant differences between, on the one hand, the experiences and perspectives of the post-Stonewall generation or Generation Q and, on the other, "those of the lesbians, gay men, bisexuals, and transgendered people who came before [them]." At the same time, however, I suggest that the differences are not those in kind but by degree - and, to borrow their metaphor, that "the chasm" separating the generations is not as deep as they imagine it to be. In saying this, I have in mind D'Emilio's argument that "radical gay liberation [during the 1970s] transformed the meaning of 'coming out.' Before Stonewall, the phrase had signified the acknowledgment of one's sexuality to others in the gay world; after Stonewall, it meant the public affirmation of homosexual identity" (Making 244). Bernstein and Silberman's explanation strongly suggests a desire for the public affirmation of their absolute difference from their "straight peers," and, more problematically, from their "gay forebears" tout court. Put another way, I sense on their part a need to seek the public affirmation of their identity from mainstream culture, without, unfortunately, also expressing an equally important need to seek the acknowledgment of their identity from others in the gay social world.

I propose an attempt to recuperate the pre-Stonewall definition of coming out as the acknowledgment of one's identity to others within gay male culture. My proposal should not be interpreted as 
wistful nostalgia but, rather, as a genuine strategy for gay men and members of Generation $Q$ alike to regain a sense of our historicity. We need to consider the act of "coming out" also as an act of "going in," a felicitous redefinition of the closet I borrow from author and playwright Neil Bartlett. In his "experimental first-person narrative" (Chisholm), Who Was That Man?: A Present for Mr Oscar Wilde, Bartlett describes his move to London in the 1980s, and recalls his amazement at discovering that he is able to claim his gay identity largely because others before him had done so already throughout the last century. He explains his life- transforming epiphany: "Perhaps my life in this city is not so much individual and natural as collective and determined ... I find myself in ... the world of other men. I didn't so much 'come out' as 'go in,' since at the very moment at which we come out, declare our difference from the world, we immerse ourselves in ... gay society" (206). In reimagining "coming out" simultaneously as "going in," Bartlett reveals a deep understanding of the historicity of the closet. For him, coming out enables him not only to declare his "difference from the world" of heterosexuals, but also to immerse himself in - through the acknowledgment of an already existing gay culture. Unlike Bernstein and Silberman, Bartlett views the past not as a distant memory, nor does he view its relation to the present as an unbridgeable chasm. On the contrary, he values the experiences and the perspectives of others who came before him, recognizing that his present-day gay male identity has been profoundly shaped by, and continues to be deeply embedded in, the history of homosexuality. Moreover, unlike Kantrowitz in his "Letter to the Queer Generation," Bartlett reconceptualizes history not as the past per se, nor as something to be superceded. Instead, he searches the past for models to emulate rather than to rebel against. I will have more to say about Bartlett in my conclusion, and, more specifically, about his innovative use of the generation concept in Who Was That Man? For the moment, however, I return to the ways in which the language of generations not only informs the shifts in consciousness about the meaning and value of the coming-out process, but also the shifts in the cultural perception of Stonewall.

Each year, we are reminded of these shifts as we witness the transformation of Stonewall into commercial spectacles at Pride celebrations. For example, during the 25 th anniversary celebrations commemorating the event, in New York City in June 1994, Out 
magazine sold T-shirts bearing the slogan "Stonewall 25: New and Improved for the 90s," a prime example of cultural amnesia that led many in attendance to join a countermarch, organized by the New York Chapter of ACT UP, as "a challenge to the rainbow-drenched official Stonewall parade" and "to protest not only the ongoing and deadly inattention to AIDS, but also, and more pointedly, the commercialization of this historical marker as a rather cynical improvement on the original" (Clarke 47-48). In a different manner, our perceptions of Stonewall have also changed because we have been encouraged to consider it as one of many defining moments, rather than as the sole defining moment of gay liberation. Novelist John Rechy, among others, has rightly called our attention to the fallacy of "the arbitrary demarcation of generations that emerged out of the emphasis on the Stonewall riots - before it, all repressed; after it, all liberated." There were "many other 'riots' before Stonewall" (including the Black Cat raids in San Francisco in the 1950s), Rechy explains, and the "emphasis on that one admittedly important event to the exclusion of others contributes to the sense of separation between generations" (qtd. in Modleski 325). That the critically-challenged Out magazine and the critically-savvy Rechy frame their separate claims about Stonewall in the language of generations - the former, implicitly; the latter, explicitly - again illustrates the complete saturation of the generation concept in contemporary gay male culture. In short, the concept remains deeply embedded within - indeed, structures - our consciousness of the gay social world. No longer an undisputed signifier, Stonewall remains a common frame of reference only because gay men no longer share a common view of it: for those at Out magazine, a misguided occasion to mark their disaffiliation from the past; for Rechy, a serious invitation to consider other watershed moments in the gay liberation movement. The generation concept profoundly shapes gay men's different valuations of Stonewall because it continues to represent an emblematic "queer fiction of the past" (see Bravmann 68-96). These shifts in consciousness concerning Stonewall illustrate that, depending on their generation location, gay men approach in different and competing ways the material and data that make up the gay male cultural archive.

To the extent that the Stonewall riots made available forms of historical consciousness to gay men in the 1970 s and 1980 s, the 
human toll of the AIDS epidemic in the last two decades threatened to obliterate them with equal force. From the early 1980 s to the mid 1990s, the AIDS epidemic radically changed gay men's relation to discourses of generation. In a variety of genres, from memoir and autobiography to cultural criticism and theory, many have written eloquently about the inextricable connection between the AIDS epidemic and the generation concept. For example, Paul Monette begins Borrowed Time: An AIDS Memoir with the following confession: "The magic circle my generation is trying to stay within the borders of is only as real as the random past. Perhaps the young can live in the magic circle, but only if those of us who are ticking will tell our story. Otherwise it goes on being $u s$ and them forever, built like a wall higher and higher, till you no longer think to wonder if you are walling it out or in" (6). The late cultural critic Thomas Yingling also expressed his views about the disproportionate but all too real effects of HIV/AIDS on different generations of gay men, writing, in 1991: "It remains to be seen whether the numbers of younger gay men ... who have joined the battle against AIDS will continue their political work [into the future]. Certainly they, too, know people infected and dying, dead or at risk, but as a generation they could choose to avoid AIDS, to see it as the issue of an older generation of gay men" (294). Born only five years apart, Monette (b. 1945) and Yingling (b. 1950) would undoubtedly claim their membership to the Stonewall generation - the first to have experienced the triumphant joys of the gay rights movement in the 1970s, and also the first to have experienced the devastating losses of the AIDS epidemic in the 1980s. Their self-reflexive sense of historicity leads them to worry not only that the generation gap in gay male culture will widen as a direct result of the AIDS epidemic, but, even more terrifying, that HIV/AIDS, in decimating the preStonewall and Stonewall generations, will render moot the idea of a generation gap. The intelligibility of the "gay generation gap" whether in the present or in the past - ultimately depends upon the existence of more than one cohort group at any historical moment.

That AIDS has been nearly all but evacuated from mainstream and gay male public consciousness attests, unfortunately, to the uncanny prescience of Monette's and Yingling's observations: what was once termed an "epidemic of signification" (see Treichler) has since been transformed into what is being termed the "end-of-AIDS" 
or "post-AIDS" discourse (see Román). The absence of historical memory concerning the AIDS epidemic is most prevalent among members of Generation Q who resist gay male identity in favor of a postgay identity, and, since the introduction of protease inhibitors as viable drug treatments for HIV/AIDS, of a post-AIDS identity. Generation Q's resistance to gay male identity in itself does not adequately explain the rise in recent years of HIV-infection and unsafe sexual practices among its constituency. Members of Generation $\mathrm{Q}$ offer conflicting reasons for this phenomenon. According to Bernstein and Silberman, "Generation Q is the first with no memory of sex before AIDS. We came out in the mid eighties or later, after Rock Hudson became ill and AIDS hit the mainstream media. For us, sex, love, queerness, and AIDS have been inextricably linked from the very beginning" (xvi). Others situated within the same generation location, however, reject what they see as the equation between gayness, sexual liberationism, and promiscuity: "It has finally occurred to Generation $Q$ that [in order] to make any significant progress in our own lives (call it greedy, if you like) it's time for gay men to stop thinking with their dicks (excuse the expression) and start thinking about the future. The buzzword, so to speak, of Generation Q has been POST GAY" (qtd. in Castiglia 152). These different views serve as useful reminders that members of similar generation locations are not - nor should we expect them to be - homogenous. More importantly, these views strongly suggest that members of Generation $Q$ have a uniquely paradoxical relationship to the AIDS epidemic. It is certainly true that, in the last two decades, younger gay men's recognition and acceptance of their same-sex desires have been shaped by the fear of sexual risk of HIV. But it is equally true that since protease inhibitors began extending lives, a generation of younger gay men have come of age with the misguided perception of the AIDS epidemic as a chronic, manageable problem, rather than as an enduring health and social crisis that demands our unwavering attention. Generation Q's consciousness of the AIDS epidemic remains radically different from that of previous generations because devastating loss and mourning have not directly and intimately shaped its members' awareness of HIV/AIDS.

The AIDS epidemic has prevented gay men from creating and sustaining a viable intergenerational culture. While the last two 
decades have certainly heightened our awareness of the need to preserve a sense of collective memory and identity, they have also heightened our awareness of the difficulties of doing so. In The Trouble with Normal, Michael Warner explains the problem of queer generations in the following way:

One reason why we have not learned more from [the history of AIDS and AIDS activism] is that queers do not have the institutions for common memory and generational transmission around which straight culture is built. Every new wave of queer youth picks up something from its predecessors but also invents itself from scratch. Many are convinced that they have nothing to learn from the old dykes and clones and trolls, and no institutions - neither households nor schools nor churches nor political groups - ensure that this will happen. And since the most painfully instructed generation has been decimated by death, the queer culture of the present faces more than the usual shortfall in memory. Now younger queers are told all too often that a principled defense of nonnormative sex is just a relic of bygone "liberationism." This story is given out in bland confidence, since so many of the people who would have contradicted it have died. (51-52)

That gay male culture struggles to create and sustain viable forms of generational consciousness further complicates the transmission of "sexual lifeways," which Andrew Hostetler and Gilbert Herdt define as "the culturally specific erotic ideas and emotions, sexual/ gender categories and roles, and theories of being and becoming a full social person that together constitute life-course development within a particular sexual culture" (264). For these reasons, gay men need to commit themselves to struggles over patterns of cultural continuity precisely because of their exclusion from normative reproductive culture.

\section{VI}

I offer two final observations about the challenges we face as we continue to examine gay male generation trouble, as well as a strategy for addressing those challenges via a reading of Neil Bartlett's innovative use of the generation concept in Who Was That Man? First, in my view, Generation Q - both as a concept and as a social 
constituency - embodies some of the contradictions and challenges of what I have been describing as generation trouble. The preferred name of Generation $Q$ as a constituency - or its obverse, the queer generation - joins together two terms that have opposing functions: the term generation suggests a social body with a distinct identity that, in many respects, contradicts the nonidentitarian principles that many find valuable in the term queer. That members of Generation $\mathrm{Q}$ fail to see this as a problem - one, I should add, that invites rather than hinders serious reflection - is symptomatic of their seeming lack of knowledge that generation and queer are terms whose respective histories predate the emergence of Generation $Q$ as a social constituency. Arguably, Generation Q emerged and gained currency around the same time that the term "queer" appeared in the academy as a theoretical category that effectively opposed not only heterosexuality but also, more broadly, various "regimes of the normal" (Warner, Fear xxvi). Indeed, critics and theorists who have begun to include the generation concept in their analyses of gay male identity and culture often do so within the framework of the disciplinary transition from gay studies to queer theory (Escoffier 121-24). I have found their analyses helpful as a starting point, though, as I have shown throughout this article, gay male generation trouble far exceeds the boundaries of the academy. In short, there exists a complex relationship between, on the one hand, self-reflexive critiques of heteronormativity by queer theorists and by activists in groups such as ACT UP, Queer Nation, and Sex Panic!, and, on the other, the unselfconscious co-optation of the term "queer" in gay popular culture.

This relationship, moreover, demonstrates that generational contracts function differently in gay male culture than in other sociocultural contexts. In saying this, I have in mind generation theorist José Ortega y Gasset's differentiation between the two main kinds of generational periods in history. According to Ortega, "ages of accumulation" signify periods of continuity, whereby the younger generation accepts its inheritance from previous generations; conversely, "ages of elimination and dispute" signify periods of rupture, whereby the younger generation rejects its inheritance (1718). Gay male generation trouble presents a scenario that does not quite fit Ortega's schematization. Unarguably, particular social and historical events have certainly contributed to the production of gay 
male generation trouble, just as much as they have to the creation of other forms of generational consciousness in other sociocultural contexts. But gay men have had to negotiate differently their acceptance and/or rejection of their inheritance from previous generations, not only because of their exclusion from normative reproductive culture but also because of their experience of the AIDS epidemic. The very existence of Generation Q - and, specifically, its members' conjoining of two terms that have opposing functions - suggests that processes of accumulation and elimination are not so easily distinguishable in gay male culture, precisely because it lacks the institutions of common memory necessary for securing and sustaining its sense of cultural heritage across generations.

My reflections on gay male generation trouble return me to Mannheim's suggestion that "the unity of generations is constituted essentially by a similarity of a number of individuals within a social whole" (365). Specifically, I want to suggest that the "location relationships" between gay men underscore not only the different ways that many of us approach, assimilate, or apply the material or data available to us, whether within or outside the context of gay male culture, but they also show that the generation concept itself figures prominently as part of that very archive of materials and data. Put another way, and this is my second concluding point, the generation concept works not only on a discursive level but on a metadiscursive level as well. In the former sense, the generation concept shows that age or generational differences do shape gay men's relation to their cultural traditions and history. In the latter sense, gay men of different age groups or generational constituencies use the generation concept for radically different purposes. They explicitly make mention of the generation concept - in all its guises - in order to make those very differences visible to begin with. Although it might be argued that this is part and parcel of the generation concept - what generational constituency does not use the concept for various purposes? - I maintain that gay men's uses of the concept demonstrate far more complex operations than other generational constituencies. Whereas generations are defined, in nongay contexts, solely by specific historical circumstances, in gay male culture, the term "generation" must itself appear in the formulation. In short, "generation" appears as a term that periodizes gay male history even as it secures gay men's sense of identity and 
social belonging based on that process of periodization. If we are truly interested in understanding how the problem of generations "can only be solved on the basis of a strict and careful analysis of all its component elements" (Mannheim 395), then we need to be vigilant in evaluating the ways in which Stonewall, the AIDS epidemic, and Generation Q trouble our understanding of gay male identity formations and social belonging. In my view, Stonewall, the AIDS epidemic, and Generation $Q$ are connected less because they are foundational touchstones of gay history in the last several decades, but more so because, in each case, the generation concept modified and helped to shore up our interpretations of those very touchstones.

I end with a final strategy for future theoretical elaborations of gay male generation trouble. In a recent article entitled "Is Kinship Always Already Heterosexual?" Judith Butler proposes a "doubleedged" mode of critical thinking about gay kinship and gay marriage that is equally relevant for addressing the concerns I have established in this article. According to Butler, we need to possess an understanding of the terms that structure debates relating to gay sexual life; and, at the same time, we need also to refuse to allow those very same terms to circumscribe the parameters or to determine the outcome of those debates. "If we engage the terms that these debates supply," she argues, "then we ratify the frame at the moment in which we take our stand. And this signals a certain paralysis in the face of exercising power to change the terms by which such topics are rendered thinkable" ("Is Kinship" 40). The further elaboration of gay male generation trouble requires a similar strategy of critical thinking. As I have shown, I am anxious about the relative ease and haste with which members of Generation $Q$ seek to differentiate themselves from previous gay generations. And I am equally anxious about the misguided perception, such as those proposed by Out magazine in its October 2001 issue, that the "gay generation gap" is a foregone conclusion. Both of these tendencies fail to engage in a Butlerian mode of "double-edged" critical thinking. As we continue to engage in debates about the possibility of a "gay generation gap," and about whether gay male and queer generations are different in kind or only by degree, we need to be especially cautious not to allow the generation concept itself to become, in the end, the sole determining measure of our identity formations. 
Ultimately, I am hopeful that the definitional and usage problems of the generation concept will motivate us in pursuing, rather than deter us from investigating, gay male generation trouble. I conclude my reflections with yet another strategy drawn from Neil Bartlett's Who Was That Man? In his attempt to examine Oscar Wilde's pivotal role in the history of homosexuality in London, Bartlett explicitly uses the generation concept in an innovative - and conditional fashion: that is, he strategically collapses the distinction between the biological-genealogical and the sociohistorical dimensions of the generation concept to enrich his understanding of the history of homosexuality - and, also, of his social membership within that history. He explains his interpretation of history and his approach to the generation concept in the following way: "I don't dwell unnecessarily on the contradictions of Oscar's social position, or on the peculiarities of my choice of him as father and guide to the city [of London] ... I read [Wilde and about Wilde] in order to discover my solidarity with my gay peers" (35). For Bartlett, Wilde remains important precisely because he is at once father figure and peer, ancestor and cohort. Exploring Wilde's life enables Bartlett to glimpse into the mirror of the past; the view reflected back leads to his recognition that the past continues to shape, in both indelible and profound measure, his own life and those of his peers and contemporaries. Rather than pose the query "Is There a Gay Generation Gap?" we should instead take Bartlett's cue and step back to consider a more pressing query - one that allows us to reflect not only upon the present-day relationship between gay male and queer generations, but also upon their connections to past generations. In order for us to understand who we are, we need also wonder: Who were those men?

I thank John Plews (and the journal's referees), Martin Ponce, and Raymond Ricketts for their thoughtful suggestions and comments to earlier drafts of this article. For financial support, I acknowledge a Doctoral Fellowship from the Social Sciences and Humanities Research Council of Canada, and a Qualls Dissertation Fellowship from Dr. Caroline Huber and the Rutgers University Foundation. 


\section{Works Cited}

Adam, Barry D. "Age Preferences Among Gay and Bisexual Men." GLQ 6 (2000): 413-33.

Bartlett, Neil. Ready to Catch Him Should He Fall. New York: Plume, 1992.

- Who Was That Man?: A Present for Mr Oscar Wilde. London: Serpent's Tail, 1988.

Bernstein, Robin, and Seth Clark Silberman. Generation Q: Gays, Lesbians, and Bisexuals Born around 1969's Stonewall Riots Tell Their Stories of Growing Up in the Age of Information. Los Angeles: Alyson, 1996.

- Introduction. Bernstein and Silberman xv-xix.

Blasius, Mark, and Shane Phelan. Introduction to Arnie Kantrowitz's "Letter to the Queer Generation." We Are Everywhere: A Historical Sourcebook of Gay and Lesbian Politics. New York: Routledge, 1997. 812.

Bravmann, Scott. Queer Fictions of the Past: History, Culture, and Difference. Cambridge, UK: Cambridge University Press, 1997. Brooks, David. “The Organization Kid." The Atlantic Monthly Apr. 2001: 40-46, 48-54.

Butler, Judith. Gender Trouble: Feminism and the Subversion of Identity. New York: Routledge, 1990.

_. "Imitation and Gender Insubordination." inside/out: Lesbian Theories, Gay Theories. Ed. Diana Fuss. New York: Routledge, 1991. 13-31.

_. "Is Kinship Always Already Heterosexual?" differences 13 (2002): 14-44.

Byrd, Robert, dir. Generation Q. Testing the Limits for Independent Television Service, 1995.

Castiglia, Christopher. "Sex Panics, Sex Publics, Sex Memories." boundary 227 (2000): 149-75.

Chin, Justin. "Q-Punk Grammar.” Bernstein and Silberman 237-39. Rpt. in Mongrel: Essays, Diatribes, and Pranks. New York: St. Martin's, 1999. 31-43.

Chisholm, Dianne. "City of Collective Memory." GLQ 7 (2001): 195243.

Clarke, Eric O. Virtuous Vice: Homoeroticism and the Public Sphere. Durham: Duke University Press, 2000. 
Coupland, Douglas. Generation X: Tales for an Accelerated Culture. New York: St. Martin's, 1991.

D’Emilio, John. Making Trouble: Essays on Gay History, Politics, and the University. New York: Routledge, 1992.

- Sexual Politics, Sexual Communities: The Making of a Homosexual Minority in the United States, 1940-1970. Chicago: University of Chicago Press, 1998.

Duberman, Martin. Stonewall. New York: Plume, 1993.

Edwards, Brent Hayes. "The Uses of Diaspora." Social Text 19.1 (2001): 45-73.

Erikson, Erik H. Childhood and Society. New York: Norton, 1993.

Escoffier, Jeffrey. American Homo: Community and Perversity. Berkeley: University of California Press, 1998.

Freeman, Elizabeth. "Packing History, Count(er)ing Generations." New Literary History 31 (2000): 727-44.

Fuss, Diana. Essentially Speaking: Feminism, Nature \& Difference. New York: Routledge, 1989.

"Generations of Trailblazers: How Yesterday's Pioneers Sparked Today's Heroes." Spec. double issue of Advocate July-Aug. 1997.

Glatze, Mike, and Benjie Nycum. "Youthquake." Out Oct. 2001: 54, $56,60,62$.

Greenberg, David F. The Construction of Homosexuality. Chicago: University of Chicago Press, 1988.

Halperin, David M. "How to Do the History of Male Homosexuality." GLQ 6 (2000): 87-123.

. One Hundred Years of Homosexuality and Other Essays on Greek Love. New York: Routledge, 1990.

Hayden, Corinne P. "Gender, Genetics, and Generation: Reformulating Biology in Lesbian Kinship." Cultural Anthropology 10 (1995): 41-63.

Heller, Dana. "The Anxiety of Affluence: Movements, Markets, and Lesbian Feminist Generation(s)." Looser and Kaplan 309-26.

Herdt, Gilbert H., and Andrew Boxer. Children of Horizons: How Gay and Lesbian Teens Are Leading a New Way Out of the Closet. Boston: Beacon, 1993.

Herman, Peter C., ed. Day Late, Dollar Short: The New Generation and the New Academy. Albany: State University of New York Press, 2000. 
Hippler, Mike. "The Problems and Promise of Gay Youth." Advocate. 16 Sept. 1986: 42-47, 55-57.

Hostetler, Andrew J., and Gilbert H. Herdt. "Culture, Sexual Lifeways, and Developmental Subjectivities.” Social Research 65 (1998): 249-90.

Howe, Neil, and William Strauss. Millennials Rising: The Next Great Generation. New York: Vintage, 2000.

Jaeger, Hans. "Generations in History: Reflections on a Controversial Concept." History and Theory 24 (1985): 273-92.

Kantrowitz, Arnie. "Letter to the Queer Generation." Rpt. in We Are Everywhere: A Historical Sourcebook of Gay and Lesbian Politics. Eds. Mark Blasius and Shane Phelan. New York: Routledge, 1997. 812-17.

Kantrowitz, Barbara, and Keith Naughton. "Generation 9-11." Newsweek 12 Nov. 2001: 46-48, 49-54, 56.

Kertzer, David I. "Generation as a Sociological Problem." Annual Review of Sociology 9 (1983): 125-49.

Kotre, John. Outliving the Self: Generativity and the Interpretation of Lives. Baltimore: Johns Hopkins University Press, 1984.

Kriegel, Annie. "Generational Difference: The History of an Idea." Dadalus 107.4 (1978): 23-38.

Litvak, Joseph. "Pedagogy and Sexuality." Professions of Desire: Lesbian and Gay Studies in Literature. Eds. George E. Haggerty and Bonnie Zimmerman. New York: MLA, 1995. 19-30.

Looser, Devoney, and E. Ann Kaplan, eds. Generations: Academic Feminists in Dialogue. Minneapolis: University of Minnesota Press, 1997.

Mannheim, Karl. "The Problem of Generations." From Karl Mannheim. Ed. Kurt Wolff. New Brunswick, NJ: Transaction, 1993. 351-95.

Marías, Julián. Generations: A Historical Method. University, AL: University of Alabama Press, 1970.

Martinez, Paula. "The Gay Generation Gap." PlanetOut Page. 15 Aug. $2002<$ http://www.planetout.com/news/feature.html? sernum $=390>$.

Modleski, Tania. "The Final Frontier: A Roundtable Discussion." Queer Frontiers: Millennial Geographies, Genders, and Generations. Eds. Joseph A. Boone et. al. Madison: University of Wisconsin Press, 2000. 316-39. 
Monette, Paul. Borrowed Time: An AIDS Memoir. New York: Avon, 1988.

Morale, Mark. Letter. Out Dec. 2001: 10.

Nardi, Peter M. Gay Men's Friendships: Invincible Communities. Chicago: University of Chicago Press, 1999.

Nash, Laura L. "Concepts of Existence: Greek Origins of Generational Thought." Dadalus 107.4 (1978): 1-21.

Ortega y Gasset, José. The Modern Theme. New York: Harper, 1961. Quinn, Jay. The Mentor: A Memoir of Friendship and Gay Identity. New York: Haworth, 2000.

Robbins, Alexandra, and Abby Wilner. Quarterlife Crisis: The Unique Challenges of Life in Your Twenties. New York: Tarcher/ Putnam, 2001.

Roof, Judith. "Generational Difficulties; or, The Fear of a Barren History." Looser and Kaplan 69-87.

Román, David. "Not-about-AIDS." GLQ 6 (2000): 1-28.

Schneider, David M. A Critique of the Study of Kinship. Ann Arbor: University of Michigan Press, 1984.

Sedgwick, Eve Kosofsky. Epistemology of the Closet. Berkeley: University of California Press, 1990.

Shah, Nayan. "Sexuality, Identity, and the Uses of History." Social Perspectives in Lesbian and Gay Studies: A Reader. Eds. Peter M. Nardi and Beth E. Schneider. London: Routledge, 1998. 48190.

Signorile, Michelangelo. "What Happened to Gay?" Advocate 19 Jan. 1999: 71-81.

Spitzer, Alan B. "The Historical Problem of Generations." The American Historical Review 78 (1973): 1353-85.

Stein, Arlene. Sex and Sensibility: Stories of a Lesbian Generation. Berkeley: University of California Press, 1997.

Strauss, William, and Neil Howe. Generations: The History of America's Future, 1584-2069. New York: Morrow, 1991.

Treichler, Paula A. "AIDS, Homophobia, and Biomedical Discourse: An Epidemic of Signification." AIDS: Cultural Analysis, Cultural Activism. Ed. Douglas Crimp. Cambridge, MA: MIT, 1988. 31-70.

Warner, Michael. Introduction. Fear of a Queer Planet: Queer Politics and Social Theory. Ed. Michael Warner. Minneapolis: University of Minnesota Press, 1993. vii-xxxi. 
__ "Irving's Posterity." English Literary History 67 (Fall 2000): 773-99.

- Publics and Counterpublics. New York: Zone, 2002.

. The Trouble with Normal: Sex, Politics, and the Ethics of Queer Life. New York: Free, 1999.

Warner, Michael, and Lauren Berlant. "Sex in Public." Critical Inquiry 24 (Winter 1998): 547-66.

Weeks, Jeffrey, Brian Heaphy, and Catherine Donovan. Same Sex Intimacies: Families of Choice and Other Life Experiments. London: Routledge, 2001.

Weinstein, Steve. "The Gay Generation Gap." Out Oct. 2001: 91, 108-09.

Weston, Kath. Families We Choose: Lesbians, Gays, Kinship. New York: Columbia University Press, 1997.

Wiegman, Robyn. "Feminism's Apocalyptic Futures." New Literary History 31 (2000): 805-25.

Williams, Raymond. Keywords: A Vocabulary of Culture and Society. New York: Oxford University Press, 1983.

Yingling, Thomas. "AIDS in America: Postmodern Governance, Identity, and Experience." insidelout: Lesbian Theories, Gay Theories. Ed. Diana Fuss. New York: Routledge, 1991. 291-310. 